\title{
Maximal Oxygen Uptake Validation in Children With Expiratory Flow Limitation
}

\author{
Katherine E. Robben, David C. Poole, Craig A. Harms \\ Kansas State University
}

\begin{abstract}
A two-test protocol (incremental/ramp (IWT) + supramaximal constant-load (CWR)) to affirm max and obviate reliance on secondary criteria has only been validated in highly fit children. In girls $(n=15)$ and boys $(n=12)$ with a wide range of $\mathrm{VO}_{2} \max (17-47 \mathrm{ml} / \mathrm{kg} / \mathrm{min})$, we hypothesized that this procedure would evince a $\mathrm{VO}_{2}$-WR plateau and unambiguous $\mathrm{VO}_{2}$ max even in the presence of expiratory flow limitation (EFL). A plateau in the $\mathrm{VO}_{2}$-work rate relationship occurred in $75 \%$ of subjects irrespective of EFL There was a range in RER at max exercise for girls $(0.97-1.14$; mean $1.06 \pm 0.04)$ and boys $(0.98-1.09$; mean $1.03 \pm 0.03$ ) such that $3 / 15$ girls and $2 / 12$ boys did not achieve the criterion RER. Moreover, in girls with RER $>1.0$ it would have been possible to achieve this criterion at $78 \% \mathrm{VO}_{2} \max$. Boys achieved $92 \% \mathrm{VO}_{2} \max$ at $\mathrm{RER}=1.0$. This was true also for HRmax where $8 / 15$ girls' and 6/12 boys' $\mathrm{VO}_{2}$ max would have been rejected based on HRmax being $<90 \%$ of age-predicted HRmax. In those who achieved the HRmax criterion, it represented $\mathrm{V} \mathrm{VO}_{2}$ of $86 \%$ (girls) and $87 \%$ (boys) $\mathrm{VO}_{2}$ max. We conclude that this two-test protocol confirms $\mathrm{VO}_{2} \mathrm{max}$ in children across a threefold range of $\mathrm{VO}_{2} \max$ irrespective of EFL and circumvents reliance on secondary criteria.
\end{abstract}

El protocolo que comprende dos test (incremental en rampa (TTI) + carga constante supramaximal) (CCS) aplicado para confirmar el consumo máximo de oxigeno y obviar la dependencia de los criterios secundarios ha sido solamente validado en niñas $(\mathrm{n}=15)$ y niños $(\mathrm{n}=12)$ bien entrenados, que poseían amplios rangos de $\mathrm{VO}_{2}$ $\max (17-47 \mathrm{ml} / \mathrm{kg} / \mathrm{min})$. Nosotros hipnotizamos que este procedimiento podría evidenciar una meseta en la relación $\mathrm{VO}_{2}$-tasa de trabajo y por lo tanto indicar valores ambiguos de $\mathrm{VO}_{2}$ max incluso en niños que presentan limitaciones del flujo espiratorio (LFE). La meseta en la relación entre el $\mathrm{VO}_{2}$-tasa de trabajo ocurre en el $75 \%$ de los sujetos, independientemente de que presenten LFE. El rango de valores en la relación de intercambio respiratorio (RER) se extendió entre 0.97 a 1.14 en niñas $(M=1.06 \pm 0.04)$ y entre 0.98 a 1.09 en niños $(M=1.03 \pm 0.03)$. De esta forma, $3 / 15$ niñas y 2/12 niños no alcanzaron el criterio de RER para estimar el $\mathrm{VO}_{2}$ max. Por otra parte, en las niñas que mostraron un RER $>1.0$ hubiera sido posible alcanzar este criterio con un valor del $78 \% \mathrm{VO}_{2} \max$. Los niños alcanzaron el $92 \%$ del $\mathrm{VO}_{2}$ max con un $\mathrm{RER}=1.0$. Esta respuesta, fue observada también

Robben, Poole, and Harms are with the Depts. of Kinesiology and Anatomy and Physiology, Kansas State University, Manhattan, KS. 
para los valores de frecuencia cardiaca máxima (FCmax) en donde el $\mathrm{VO}_{2}$ max de 8/15 niñas 6/12 niños podría haber sido rechazado basándose en el criterio de FCmax ya que $<90 \%$ alcanzaron los valores de FCmax predichos a partir de la edad. De esta manera, el $86 \%$ de las niñas y el $87 \%$ de los niños alcanzaron el criterio de FCmax para estimar el $\mathrm{VO}_{2}$ max. Se concluye que el protocolo de dos test es útil para confirmar los valores de $\mathrm{VO}_{2}$ max en niños a través de un triple rango de valores máximos independientemente de LFE y evita la dependencia de los criterios secundarios.

The most widely accepted criterion of fitness in humans and animals is the maximal capacity for oxygen uptake $\left(\mathrm{VO}_{2} \max \right)$. Measured during 'whole body' or, at least, large muscle mass exercise, for example cycling or running, $\mathrm{VO}_{2}$ max represents the integrated capacity of the respiratory, cardiovascular and muscle systems to uptake, transport and use $\mathrm{O}_{2}$ (e.g., ref 3, 45). Early in the 20th century Hill and Lupton (1923) demonstrated that there was a work rate (WR) or running speed above which $\mathrm{VO}_{2}$ did not increase further (rev. ref 17). This observation defined the 'plateau concept' where the lack of increase of $\mathrm{VO}_{2}$ as a function of WR or speed was deemed to provide unequivocal evidence of achievement of $\mathrm{VO}_{2} \max (4)$.

Determination of $\mathrm{VO}_{2} \mathrm{max}$ is one of the most common measurements made in clinical and experimental physiology and sports medicine. However, its quantification has become problematic, in part, because use of continuous (ramp or incremental (IWT)) testing protocols may preclude identification of a $\mathrm{VO}_{2}$ plateau or leveling-off in a substantial proportion of individuals (32). Specifically, even when continued to unambiguous fatigue, in the majority of subjects ( $\sim$ two-thirds in children, refs. 6,36) the $\mathrm{VO}_{2}$-WR relationship may be linear throughout the test or even curve upwards at high WR's without any tendency to plateau $(14,17,32)$. Thus, although the continuous test is time-efficient and can resolve important parameters of aerobic function such as the gas exchange (and lactate) threshold as well as work efficiency $(9,13,47)$, such that it is often de rigueur in exercise testing laboratories, it has not resolved ambiguity with respect to determination of $\mathrm{VO}_{2} \max (14,25,32)$.

In the absence of $\mathrm{a} \mathrm{VO}_{2}$-WR plateau and in an attempt to validate that a true $\mathrm{VO}_{2}$ max has been achieved several 'secondary' criteria have been adopted. These criteria include reaching values for respiratory exchange ratio (RER $\geq 1.10$ or 1.15 in adults, ref $32 ; \geq 1.0$ in children, ref 37 ), heart rate (HR $\leq 10 \mathrm{~b} / \mathrm{min}$ of age-predicted maximum in adults, ref $32 ; \geq 185 \mathrm{~b} / \mathrm{min}$ or $\geq 90 \%$ of age-predicted maximum in children, ref 1,37) and/or blood lactate $(8-10 \mathrm{mmol}$ in adults, ref 32 ; $\geq 9 \mathrm{mmol}$ in children, ref 7). However, because of the broad ranges of these variables at maximal exercise between, and sometimes even within, individuals including children $(3,11,39,44,45)$ their scientific veracity for discriminating $\mathrm{VO}_{2}$ max in adults has been challenged (32) and there is emerging support for a two-test procedure that has the potential to yield $\mathrm{V} \mathrm{VO}_{2}$-WR plateau (or leveling off) in all subjects $(6,14,26,32)$.

With respect to experimental and clinical exercise physiology, children present a particularly challenging population and yet determination of their $\mathrm{VO}_{2}$ max may yield crucial information regarding cardiopulmonary and muscular development and health (rev. 7,35,37). Unfortunately, the problem regarding use of secondary criteria such as RER and HR to validate $\mathrm{VO}_{2}$ max is especially acute in children and there is thus the pressing need to establish a uniform testing procedure or, at least, standard principles for identifying $\mathrm{VO}_{2}$ max rather than simply resorting to reporting the peak $\mathrm{VO}_{2}$ in this population. To this end, Barker and colleagues (6) have demonstrated 
recently that, in children of relatively high aerobic fitness (mean $\mathrm{VO}_{2} \mathrm{max} \sim 50 \mathrm{ml} /$ $\mathrm{kg} / \mathrm{min}$ ), the two test (incremental/ramp + supramaximal constant-load (CWR)) can validate achievement of $\mathrm{VO}_{2} \max$ (see also refs. 2 and 34 for use of supramaximal tests to validate $\mathrm{VO}_{2} \mathrm{max}$ ). What has not been established in children is whether this procedure is effective across the spectrum of lower fitness levels as might be expected in a randomly recruited population, for example, in the United States. It is also pertinent that among this population of prepubescent children there may be a high prevalence of expiratory flow limitation (EFL, 28,29,40) and possibly exercise-induced arterial hypoxemia (EIAH, 27). Whether the two-test protocol can effectively determine $\mathrm{VO}_{2}$ max across a broad spectrum of fitness levels and in the presence of EFL in children which, in and of itself may increase fatigability and modulate the respiratory response to exercise, has not been determined.

To address this issue in prepubertal girls and boys of widely disparate fitness levels we used a maximal incremental exercise protocol followed by a fatiguing CWR test at $105 \%$ of the highest WR achieved during the preceding incremental exercise. Whereas in adults all work rates in the severe exercise intensity domain may elicit $\mathrm{VO}_{2}$ max when exercise is continued to fatigue (30-32), this may not be the case for children $(5,6,48)$. However, we reasoned that this procedure would permit identification of $\mathrm{VO}_{2}$ max thereby making the issue of secondary criteria redundant. The presence and severity of EFL was determined on the incremental test (40). The following hypotheses were tested: 1) Irrespective of the presence of EFL and absolute aerobic fitness, completion of the two-test protocol in children is feasible and evinces a $\mathrm{VO}_{2}$ - WR plateau and unambiguous $\mathrm{VO}_{2}$ max determination, and, 2) commonly accepted criteria adopted for $\mathrm{VO}_{2} \max$ validation in children (i.e., RER $\geq 1.0$, HRmax $\geq 90 \%$ of age-predicted maximum) are erroneous and could feasibly result either in acceptance of invalid (i.e., submaximal) $\mathrm{VO}_{2} \mathrm{~s}$ or, in some cases, mandate rejection of individuals who have actually achieved $\mathrm{VO}_{2} \mathrm{max}$.

\section{Methods}

Twenty seven healthy prepubescent children (15 girls, 12 boys) ages $7-11$ years, of widely varying activity/sporting pursuits were recruited and volunteered as participants. All participants were free of asthma or airway disease determined by history and demonstrated by normal lung function measured with standard pulmonary function tests. Children were prepubescent and were in the first stage of maturation, as defined by Tanner stage 1 (41). Each child had a parent or guardian present to provide medical history information and informed consent. All research components were reviewed and approved by the Institutional Review Board of Human Subjects at Kansas State University, Manhattan, KS.

\section{Experimental Design}

A parent or guardian of the children was present during testing sessions. Height and weight were recorded using a calibrated eye-level physical scale with height rod (Detecto, Webb City, MO). Participants were then familiarized with the equipment and procedures. After several practice trials, standard pulmonary function measurements were performed using an automated pulmonary function testing system in accordance with recommended techniques. Participants then completed 
a symptom-limited incremental cycle exercise test to determine maximal oxygen uptake $\left(\mathrm{VO}_{2} \max \right)$. A second exercise test at constant work load $(105 \%$ of that achieved at exhaustion in the incremental test) was performed following $15 \mathrm{~min}$ rest designed to verify $\mathrm{VO}_{2}$ max.

\section{Pulmonary Function Tests}

Total lung capacity (TLC) and maximal flow-volume loops (MFVL) were assessed before exercise testing (SensorMedics 229 Metabolic Cart, SensorMedics Corp, Yorba Linda, CA). TLC was determined using the nitrogen wash-out technique. All tests were performed in triplicate, with the average value used in analysis.

\section{Maximal Oxygen Uptake $\left(\mathrm{VO}_{2} \mathrm{max}\right)$}

An incremental exercise test to exhaustion was performed using a cycle ergometer (Ergometer 800S, Sensor Medics Corp., Yorba Linda, CA) to determine $\mathrm{VO}_{2}$ max. Subjects were given consistent and complete instructions explaining the protocol of the test to ensure maximal volitional effort. Before testing, a 3-L calibration syringe was used to calibrate the flow sensor. Known gas concentrations that spanned the range of expected measurements were used to calibrate gas analyzers. Resting metabolic measurements were taken for three minutes. Participants then began with a warm-up for approximately two minutes at a work rate of $20 \mathrm{~W}$, pedaling between 50-60 rpm (rev/min). Children were instructed to maintain this pedaling speed while the work rate was increased by $10 \mathrm{~W}$ each minute. Participants remained seated throughout the test. Heart rate (HR) was monitored throughout the test via a four lead ECG interfaced to the metabolic software. The sensor from a pulse oximeter (Datex-Ohmeda, 3900P, Madison, WI) was secured to the left earlobe to estimate arterial oxygen saturation $\left(\mathrm{SpO}_{2}\right)$. The pulse oximeter was self calibrated before each test. The pulse oximeter supplied a visual pulse waveform to ensure adequate blood perfusion throughout the test. $\mathrm{SpO}_{2}$ values were averaged over the last minute of each exercise stage. Participants continued to exercise until reaching volitional exhaustion. Verbal encouragement was provided throughout the test. The $\mathrm{VO}_{2} \mathrm{max}$ test concluded when subjects could not maintain a pedal frequency of $>50 \mathrm{rev} / \mathrm{min}$ for five consecutive revolutions despite firm but gentle encouragement. Metabolic and ventilatory data were assessed continuously through breath-by-breath analysis (SensorMedics 229 Metabolic Cart, SensorMedicsCorp., Yorba Linda, CA) and were averaged over the last $20 \mathrm{~s}$ for each minute of exercise.

Following the $\mathrm{VO}_{2}$ max test, participants rested for 15 min and then performed a constant load $\left(105 \% \mathrm{VO}_{2} \max \right)$ exercise test until exhaustion to verify $\mathrm{VO}_{2} \max$ $(6,14,25,32)$. Verbal encouragement was provided throughout the test. Work rate for the test was determined from the final work rate (watts) during the incremental test. Participants were given a warm-up period of $90 \mathrm{~s}$ pedaling $50 \mathrm{rev} / \mathrm{min}$ at $20 \mathrm{~W}$. Work rate was increased until reaching calculated work rate $(\sim 30 \mathrm{~s})$ and subjects were instructed to maintain $50 \mathrm{rev} / \mathrm{min}$ until volitional fatigue. $\mathrm{VO}_{2}$ was averaged over the final $20 \mathrm{~s}$ of this test after it was ensured that this period did not include breaths in which $\mathrm{VO}_{2}$ was still increasing systematically.

$\mathrm{VO}_{2} \max$ was identified as a reduced slope of the $\mathrm{VO}_{2}-\mathrm{WR}$ relationship as described in principal by Day et al. (14). Briefly, a linear regression was fit to the linear portion of the IWT-derived $\mathrm{VO}_{2}$-WR response (SigmaPlot, San Jose, CA) after 
the first and last two minutes were excluded. Subsequently, the difference between the extrapolated linear fit and the measured response in the last $20 \mathrm{~s}$ before fatigue was calculated. $\mathrm{VO}_{2}$ max was defined when $\mathrm{VO}_{2}$ increased $\leq 50 \%$ that expected based on the $\mathrm{VO}_{2}$-WR relationship for that subject. This procedure was also followed for the CWR test where the last $20 \mathrm{~s} \mathrm{VO}_{2}$ was compared with that achieved on the IWT (see Figure 1). Where this procedure did not identify $\mathrm{VO}_{2}$ max these data were not (and indeed could not) be used for the subsequent analyses of RER and $\mathrm{HR}$ relative to $\mathrm{VO}_{2}$ max.
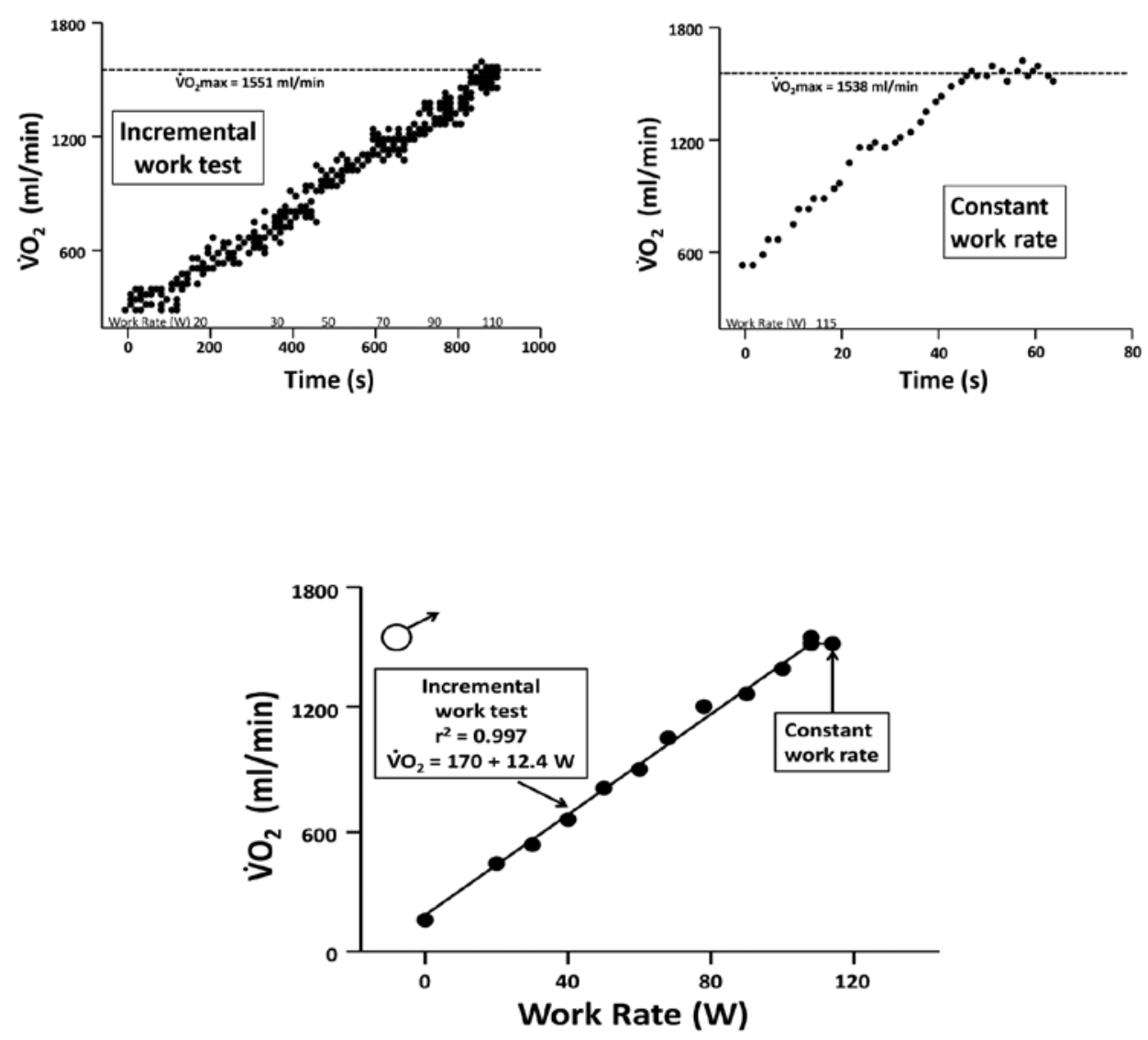

Figure 1 - Oxygen uptake $\left(\mathrm{VO}_{2}\right)$ responses to exhausting incremental and constant-load exercise used to verify that $\mathrm{VO}_{2}$ max has been achieved. Upper left panel presents breath-by-breath response to incremental exercise for 1 representative boy. Notice the absence of a plateau of $\mathrm{VO}_{2}$ against work load. Upper right panel shows the response to a work load above that achieved on the incremental test. Despite the higher work load $\mathrm{VO}_{2}$ achieves almost exactly the same value as the incremental test. Bottom panel conflates the two responses for $\mathrm{VO}_{2}(20 \mathrm{~s}$ averages $)$ against work load and demonstrates a plateau for $\mathrm{VO}_{2}$ definitive for $\mathrm{VO}_{2} \max$. 
Expiratory Flow Limitation. Tidal volume $\left(\mathrm{V}_{\mathrm{T}}\right)$ loops were recorded during incremental exercise by means of a bidirectional flow sensor in line with the gas analysis system. Each subject received a detailed explanation and demonstration of the required technique and performed at least three maximal flow-volume loop maneuvers before and immediately following exercise. Quality control was ensured by the system software and the requirement for reproducibility within 5\%. EFL was identified when the exercising VT loop intersected the maximal flow volume loop by $\geq 5 \%(10,29,40)$.

\section{Statistics}

SigmaStat statistical software (Janel Scientific Software) was used for data analysis and Bland-Altman plots were used to determine the agreement between variables (mean bias, $95 \%$ confidence intervals) in subjects for whom $\mathrm{VO}_{2}$ max was validated. Data are expressed as mean $\pm S D$. Differences were determined using ANOVA. Significance was set at $p<.05$ for all analyses.

\section{Results}

The stated objective of achieving a broad range of $\mathrm{VO}_{2}$ max values $(17-47 \mathrm{ml} /$ $\mathrm{kg} / \mathrm{min})$ was achieved. Oxygen saturation $\left(\mathrm{SpO}_{2}\right)$ was maintained within $3 \%$ of resting values in all subjects throughout exercise and was not different $(p>.05)$ between boys and girls. As shown in Table 1, despite no difference in age, weight or height between girls and boys, lung capacities (total lung capacity, TLC, forced vital capacity, FVC), volumes (residual volume, RV), and flows (peak expiratory flow, PEF, forced expiratory volume in $1 \mathrm{~s}, \mathrm{FEV}_{1}$, forced expiratory flow at $50 \%$

Table 1 Chronological, Physical and Pulmonary Function Characteristics of Subjects

\begin{tabular}{lcc}
\hline & Boys $(\boldsymbol{n}=\mathbf{1 2})$ & Girls $(\boldsymbol{n}=\mathbf{1 5})$ \\
\hline Age $(\mathrm{yr})$ & $9.6 \pm 0.8$ & $9.7 \pm 0.9$ \\
Weight $(\mathrm{kg})$ & $33.9 \pm 8.1$ & $33.0 \pm 9.4$ \\
Height (cm) & $137.1 \pm 5.2$ & $135.3 \pm 6.2$ \\
TLC (L) & $2.7 \pm 0.5 *$ & $2.1 \pm 0.5$ \\
FVC (L/sec) & $2.3 \pm 0.3 *$ & $1.9 \pm 0.4$ \\
RV (L) & $0.4 \pm 0.3 *$ & $0.2 \pm 0.1$ \\
PEF (L/sec) & $3.6 \pm 0.6 *$ & $3.0 \pm 0.5$ \\
FEV $(\mathrm{L} / \mathrm{sec})$ & $1.9 \pm 0.2 *$ & $1.6 \pm 0.3$ \\
$\mathrm{FEV}_{1} / \mathrm{FVC}(\%)$ & $85.2 \pm 6.2$ & $83.4 \pm 5.9$ \\
$\mathrm{FEF}_{50 \%}(\mathrm{~L} / \mathrm{sec})$ & $2.3 \pm 0.5 *$ & $1.9 \pm 0.5$ \\
\hline
\end{tabular}

*Significantly higher in boys $(\mathrm{p}<0.05)$.

FVC, forced vital capacity; PEF, peak expiratory flow; $\mathrm{FEV}_{1}$, forced expiratory volume in 1 sec; $\mathrm{FEF}_{50 \%}$, forced expiratory flow at $50 \%$; TLC, total lung capacity; RV, residual volume. 
total lung capacity, $\left.\mathrm{FEF}_{50 \%}\right)$ were all greater $(p<.05)$ in boys than girls. However, the ratio $\mathrm{FEV}_{1} / \mathrm{FVC}$ was not significantly different between sexes. EFL occurred in $14 / 15$ girls and $11 / 12$ boys and, where present, encompassed $47 \pm 6 \%$ (range $15-80 \%$ ) and $61 \pm 4 \%$ (range 10-85\%) of $\mathrm{V}_{\mathrm{T}}$ for girls and boys, respectively. However, there was no evidence that EFL precluded the two-test procedure from validating that $\mathrm{VO}_{2}$ max had been achieved.

\section{Girls}

A decrease of the $\mathrm{VO}_{2}$-WR slope necessary to identify $\mathrm{VO}_{2}$ max from the IWT occurred in only $2 / 15(14 \%)$ of instances. However, the group means $(n=15)$ for the IWT and CWR test $\mathrm{VO}_{2}$ 's were $1.03 \pm 0.05$ and $0.99 \pm 0.051 \mathrm{O}_{2} \cdot \mathrm{min}^{-1}(p>.05)$, respectively. These occurred at work rates of $84 \pm 4$ and $89 \pm 4 \mathrm{~W}$ and thus broadly satisfied the $\mathrm{VO}_{2}$ max criterion that an increased work rate was accomplished with no further increase in $\mathrm{VO}_{2}$ (see example for boys in Figure 1). It is pertinent that, within that data set, were two subjects for whom $\mathrm{VO}_{2}$ either increased (1.29-1.38 $\left.1 \mathrm{O}_{2} \cdot \mathrm{min}^{-1}\right)$ or decreased $\left(1.03-0.891 \mathrm{O}_{2} \cdot \mathrm{min}^{-1}\right)$ substantially from IWT to CWR thereby preventing the CWR test from verifying that $\mathrm{VO}_{2} \mathrm{max}$ had been achieved. Without these subjects (i.e., $n=13$ ) inspection of the mean (IWT $1.03 \pm 0.05$, CWT $1.00 \pm 0.061 \mathrm{O}_{2} \cdot \mathrm{min}^{-1}, p>.05$ ) and individual (mean of individual deltas $0.05 \pm 0.01 \mathrm{O}_{2} \cdot \mathrm{min}^{-1}$ ) subject data revealed excellent correspondence between the IWT and CWR tests. The Bland-Altman plot in Figure 2 illustrates the individual correspondence between the highest $\mathrm{VO}_{2}$ achieved on the IWT and CWR tests.

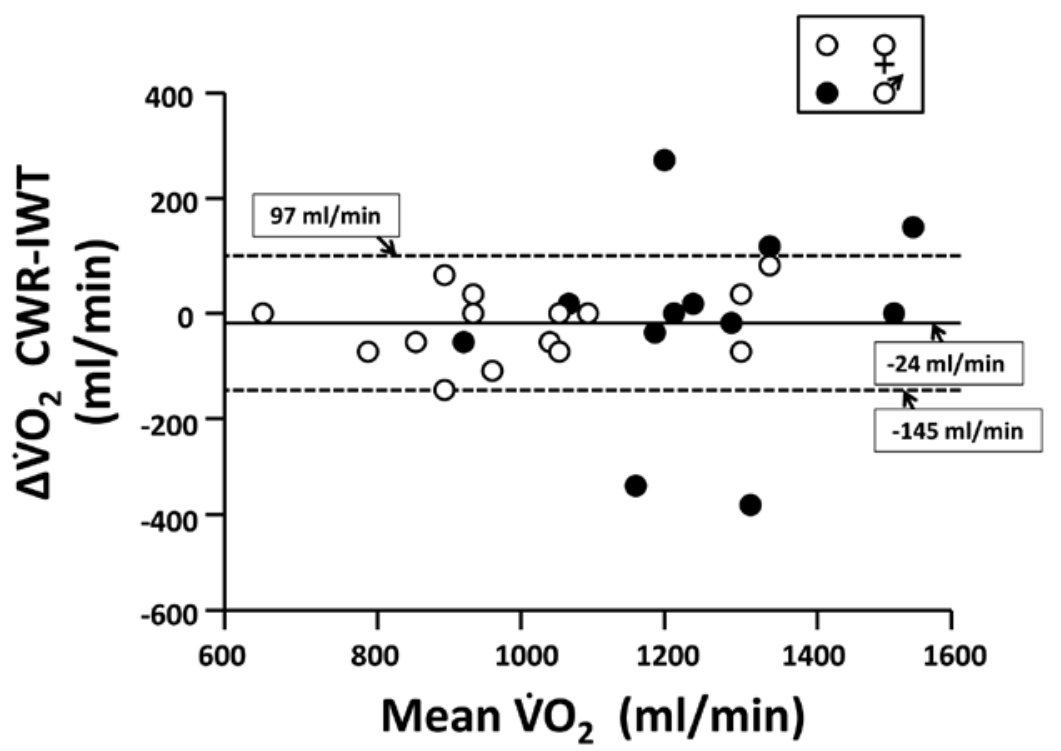

Figure 2 - Bland-Altman plot depicting oxygen uptake $\left(\mathrm{VO}_{2}\right)$ difference between the highest $\mathrm{VO}_{2}$ achieved on the supramaximal constant work rate (CWR) and incremental work rate (IWR) tests for each subject. Mean bias is given by the solid line and $95 \%$ confidence intervals are dotted lines. 
Use of 'Secondary' Criteria. RER. 3/15 subjects failed to achieve an RER $\geq 1.0$ and yet each of these demonstrated a plateau of the $\mathrm{VO}_{2}$-WR relationship. In addition, one subject whose $\mathrm{VO}_{2}$ increased substantially (7\%) from the IWT to the CWR elicited an RER of 1.14 on the IWT. For those subjects who achieved the criterion $\operatorname{RER}(n=12)$ it was possible to do so at $78 \% \mathrm{VO}_{2} \max$ (Figure 3$)$. The Bland-Altman plot (Figure 4) denotes the potential for underestimation of $\mathrm{VO}_{2}$ max possible using the $\mathrm{RER}=1.0$ criterion for all subjects in whom $\mathrm{VO}_{2}$ max was validated and RER reached 1.0 or higher. 2. HR. Eight subjects did not fulfill the HR criterion on the IWT and yet seven of these demonstrated a plateau of the $\mathrm{VO}_{2}-\mathrm{WR}$ relation. Moreover, the highest IWT HR recorded for any girl (205 b/min) was achieved on an IWT that did not evoke $\mathrm{VO}_{2} \max$ (i.e., 1.29 (IWT) vs. 1.38 (CWR) $1 \mathrm{O}_{2} \cdot \mathrm{min}^{-1}$ ). In those seven subjects eliciting a $\mathrm{VO}_{2}-\mathrm{WR}$ plateau the criterion $\mathrm{HR}$ was attained at $86 \% \mathrm{VO}_{2} \max$ (Figure 5). The Bland-Altman plot (Figure 6) denotes the potential for underestimation of $\mathrm{VO}_{2}$ max possible using the $\mathrm{HR} \geq 189 \mathrm{~b} / \mathrm{min}$ criterion for all subjects in whom $\mathrm{VO}_{2}$ max was validated and $\mathrm{HR}$ reached at least $189 \mathrm{~b} / \mathrm{min}$.

\section{Boys}

A decrease of the $\mathrm{VO}_{2}$-WR slope necessary to identify $\mathrm{VO}_{2}$ max from the IWT occurred in $3 / 12(25 \%)$ of individuals. The group means $(n=12)$ for the IWT and CWR test $\mathrm{VO}_{2} \mathrm{~s}$ were $1.26 \pm 0.19$ and $1.21 \pm 0.701 \mathrm{O}_{2} \cdot \mathrm{min}^{-1}(p>.05)$, respectively, which occurred at work rates of $96 \pm 4$ and $101 \pm 4 \mathrm{~W}$. As for the girls, these satisfied the $\mathrm{VO}_{2}$ max criterion that an increased work rate was achieved without a matching $\mathrm{VO}_{2}$ rise. Again, however, within this data set were multiple (i.e., 5) subjects for whom $\mathrm{VO}_{2}$ either increased (up to $0.28 \mathrm{l} \mathrm{O}_{2} \cdot \mathrm{min}^{-1}$ ) or decreased (up to $0.40 \mathrm{l} \mathrm{O}_{2} \cdot \mathrm{min}^{-1}$ ) thereby disqualifying the CWR test from verifying that $\mathrm{VO}_{2} \max$ was attained for these individuals. Without these subjects (i.e., $n=7$ ) the remaining cohort elicited mean (IWT 1.25 \pm 0.06 , CWT $1.23 \pm 0.071 \mathrm{O}_{2} \cdot \mathrm{min}^{-1}, p>.05$ ) and individual (mean of individual deltas $0.05 \pm 0.011 \mathrm{O}_{2} \cdot \mathrm{min}^{-1}$ ) subject data supporting achievement of $\mathrm{VO}_{2} \max$.

Use of "Secondary" Criteria. 1. RER. 2/12 subjects did not reach an RER $\geq 1.0$ although one of these elicited a $\mathrm{VO}_{2}$-WR plateau. Moreover, two subjects who did achieve an RER $>1.0$ during the IWT did so at a clearly submaximal $\mathrm{VO}_{2}$ as determined by comparison with the corresponding $\mathrm{CWR} \mathrm{VO}_{2}$ (i.e., 10-26\% higher). For those 10 subjects who achieved their criterion RER it was possible to do so at $92 \% \mathrm{VO}_{2} \max$ (Figure 3). 2. HR. Six subjects did not reach their IWT $\mathrm{HR}$ criterion but, of these, four demonstrated a $\mathrm{VO}_{2}-\mathrm{WR}$ plateau when plotting both IWT and CWR results together (as exemplified in Figure 1). There was one individual who attained the HR (and RER) criterion on an IWT that clearly did not evoke $\mathrm{VO}_{2} \max$ (i.e., 1.46 (IWT) vs. 1.61 (CWR) $1 \mathrm{O}_{2} \cdot \mathrm{min}^{-1}$ ). Those six subjects who reached their $\mathrm{HR}$ criterion did so at $87 \% \mathrm{VO}_{2} \max$ (Figure 5).

\section{Discussion}

There are many fascinating questions that remain unanswered regarding the physiology and pathophysiology of oxygen transport and utilization during growth and maturation. However, insofar as answering those questions is dependent upon 

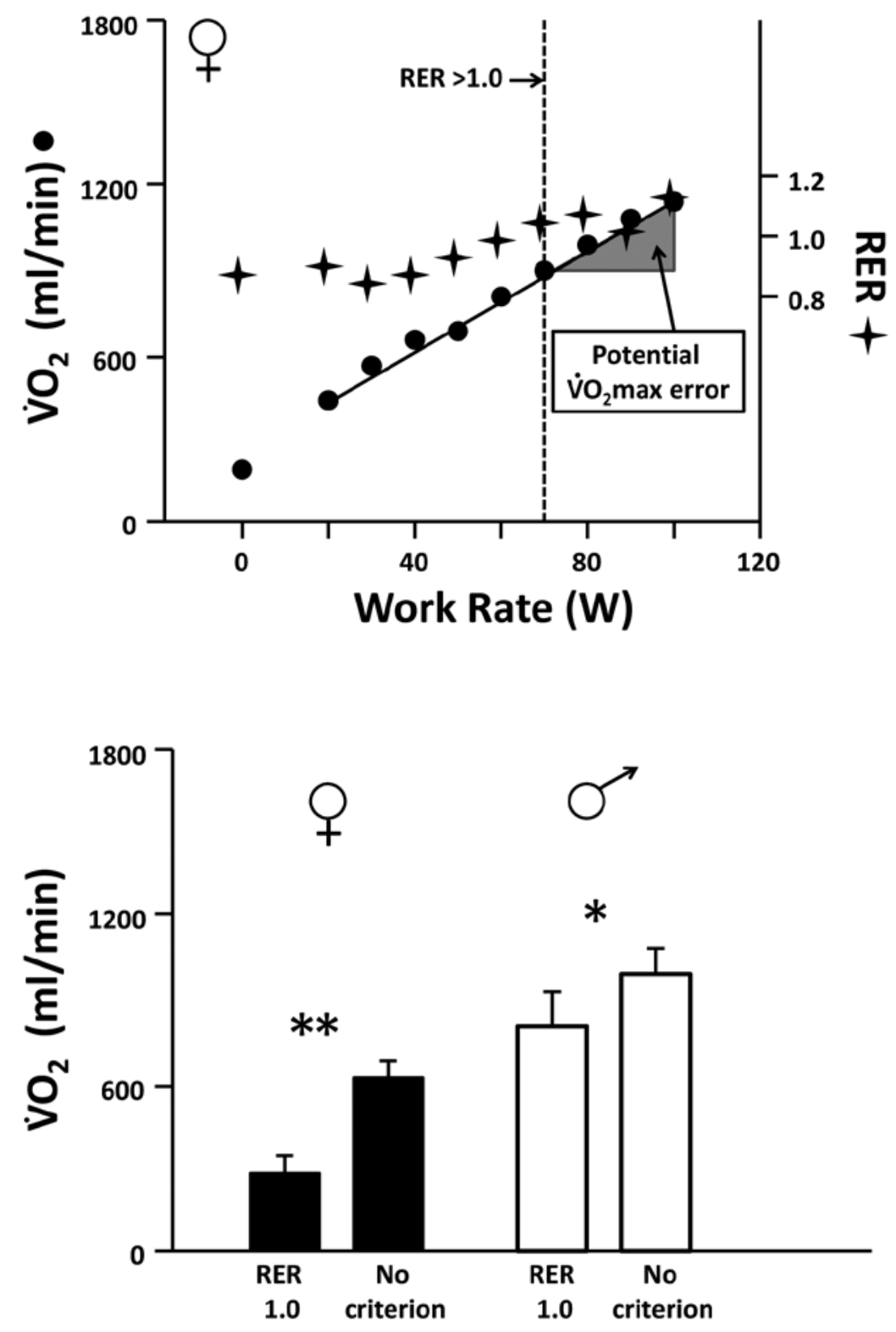

Figure 3 - Adoption of rigid respiratory exchange ratio criterion $(\mathrm{RER}=1.0)$ can result in acceptance of submaximal $\mathrm{VO}_{2}$ and thus substantial errors in $\mathrm{VO}_{2} \mathrm{max}$ measurement. Top panel demonstrates that RER can rise above 1.0 at $\sim 70 \% \mathrm{VO}_{2} \max$ for this representative girl and the bottom panel gives the average maximum underestimation of $\mathrm{VO}_{2}$ max possible for girls (left, $n=12$ )) and boys (right, $n=10$ ) from utilizing this RER criterion. ${ }^{* *} p<$ $.001,{ }^{*} p<.05$. 


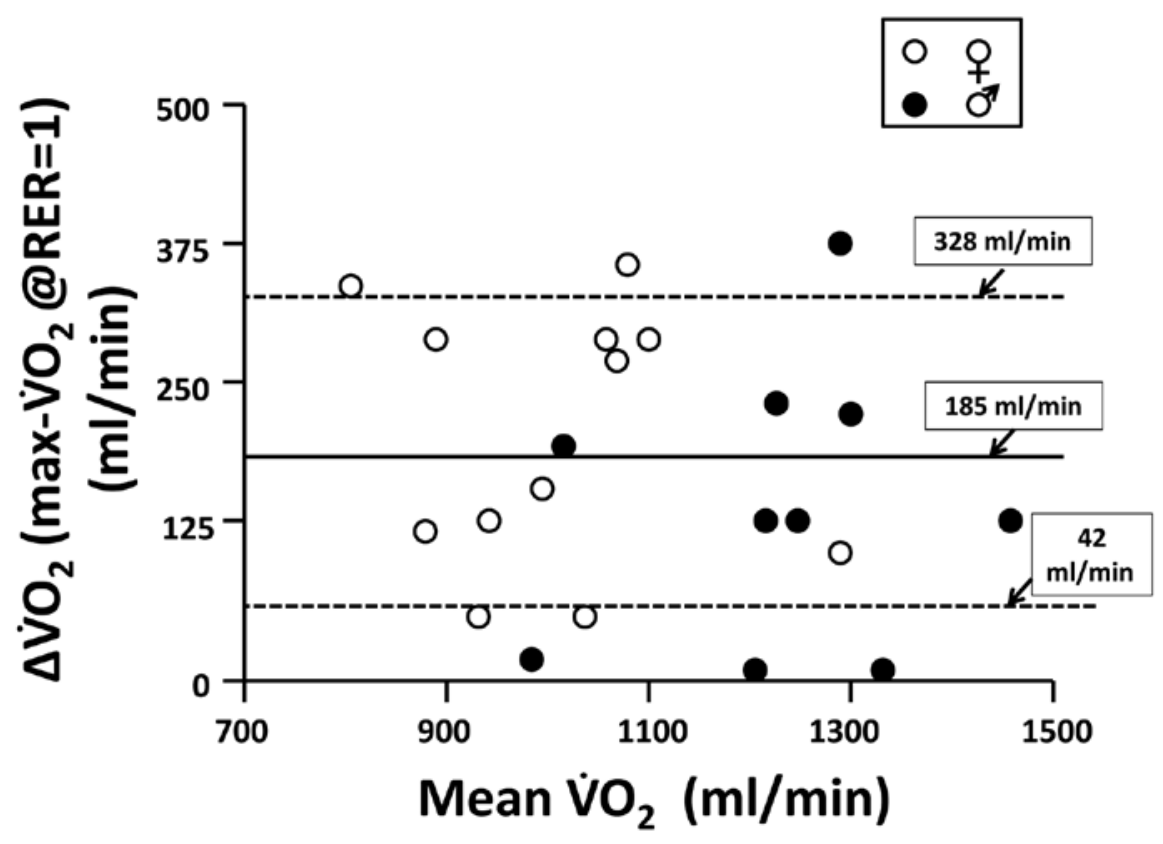

Figure 4 - Bland-Altman plot depicting oxygen uptake $\left(\mathrm{VO}_{2}\right)$ difference between $\mathrm{VO}_{2} \mathrm{max}$ (validated for these subjects using the two-test protocol) and $\mathrm{VO}_{2}$ at respiratory exchange ratio $(\mathrm{RER})=1.0$. Mean bias is given by the solid line and $95 \%$ confidence intervals are dotted lines. Note subject numbers necessarily correspond to only those subjects in whom $\mathrm{VO}_{2} \max$ was determined and RER reached at least 1.0.

accurate measurement of $\mathrm{VO}_{2} \mathrm{max}$, children present a substantial challenge; not least of which is the high prevalence of EFL in this population $(28,29,40)$. One approach has been to estimate $\mathrm{VO}_{2}$ max indirectly from submaximal tests whereas another has been to accept secondary criteria (e.g., HR, RER) to provide confidence that $\mathrm{VO}_{2}$ max has been achieved. Estimations are only as good as the assumptions made and the variability of HRmax in adults and children combined with the recent discrediting of secondary criteria for $\mathrm{VO}_{2} \max$ validation in adults $(25,32)$ and children (6) raises concerns over continuing to implement these practices. Pertinent to this issue, the principal original findings of the present investigation are that, across a broad range of aerobic fitness $\left(\mathrm{VO}_{2} \max , 17-47 \mathrm{ml} / \mathrm{kg} / \mathrm{min}\right): 1$. a two-test protocol (IWT and CWR) can yield a $\mathrm{VO}_{2}$-WR plateau and thus unambiguous determination of $\mathrm{VO}_{2} \max$ (achieved in $75 \%$ subjects herein) even concomitant with pronounced EFL. 2. RER and HR criterion cannot substantiate that $\mathrm{VO}_{2}$ max has been achieved. Rather, the high variability in peak or maximal values for RER and $\mathrm{HR}$ means that clearly submaximal $\mathrm{VO}_{2}$ values can be deemed acceptable for some individuals while mandating that data for others who may have reached $\mathrm{VO}_{2}$ max be discarded. Either eventuality is scientifically reprehensible, in part, because they erode objective discrimination and statistical power. What could not be addressed 

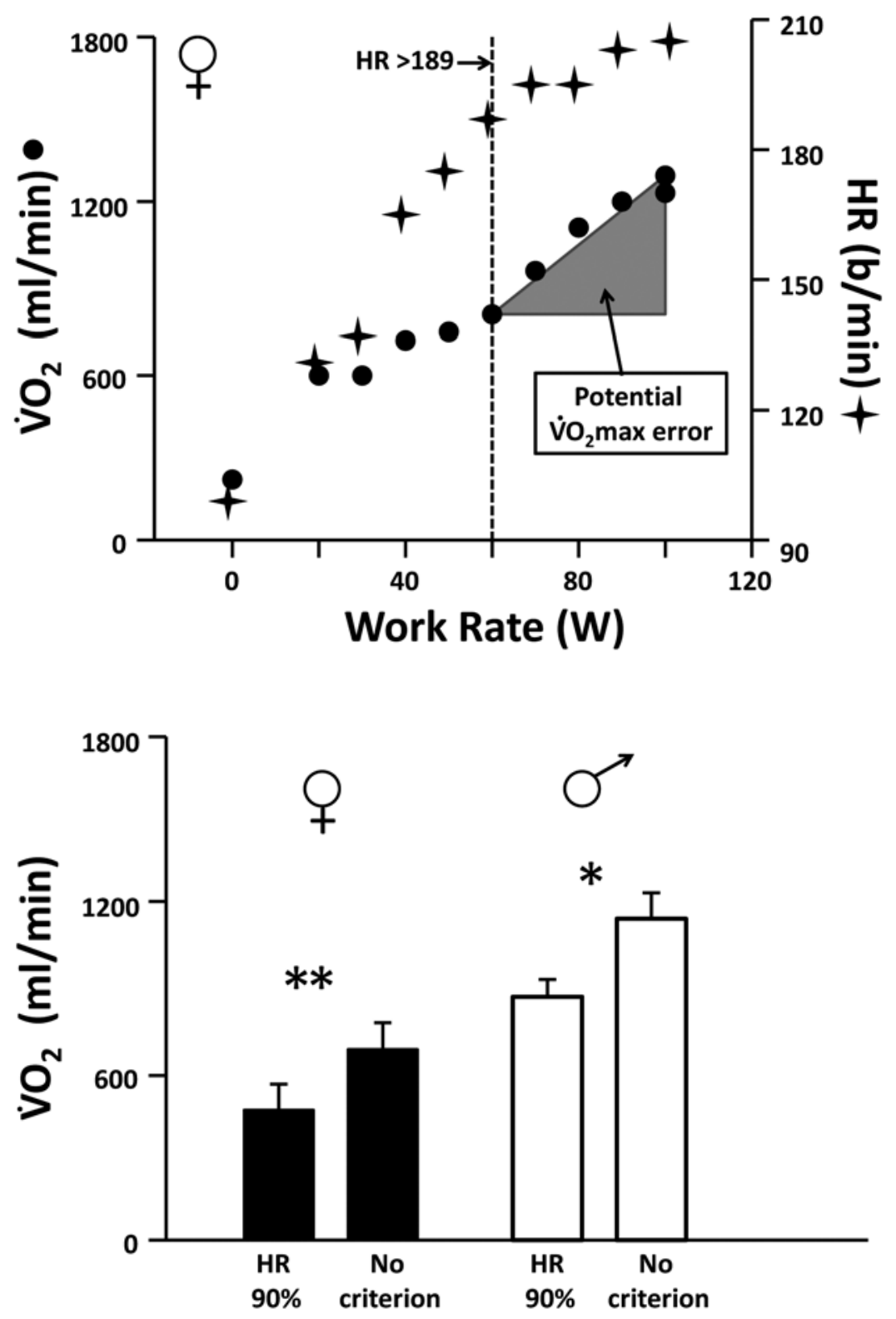

Figure $\mathbf{5}$ - Adoption of rigid heart rate criterion (90\% of age-predicted maximum) can result in acceptance of submaximal $\mathrm{VO}_{2}$ and thus substantial errors in $\mathrm{VO}_{2}$ max measurement. Top panel demonstrates that $\mathrm{HR}$ can rise above $90 \%$ max at $\sim 60 \% \mathrm{VO}_{2}$ max for this representative girl and the bottom panel gives the average maximum underestimation of $\mathrm{VO}_{2}$ max possible for girls (left, $n=7$ ) and boys (right, $n=6$ ) from utilizing this HR criterion. $* * p<.01, * p<.05$. 


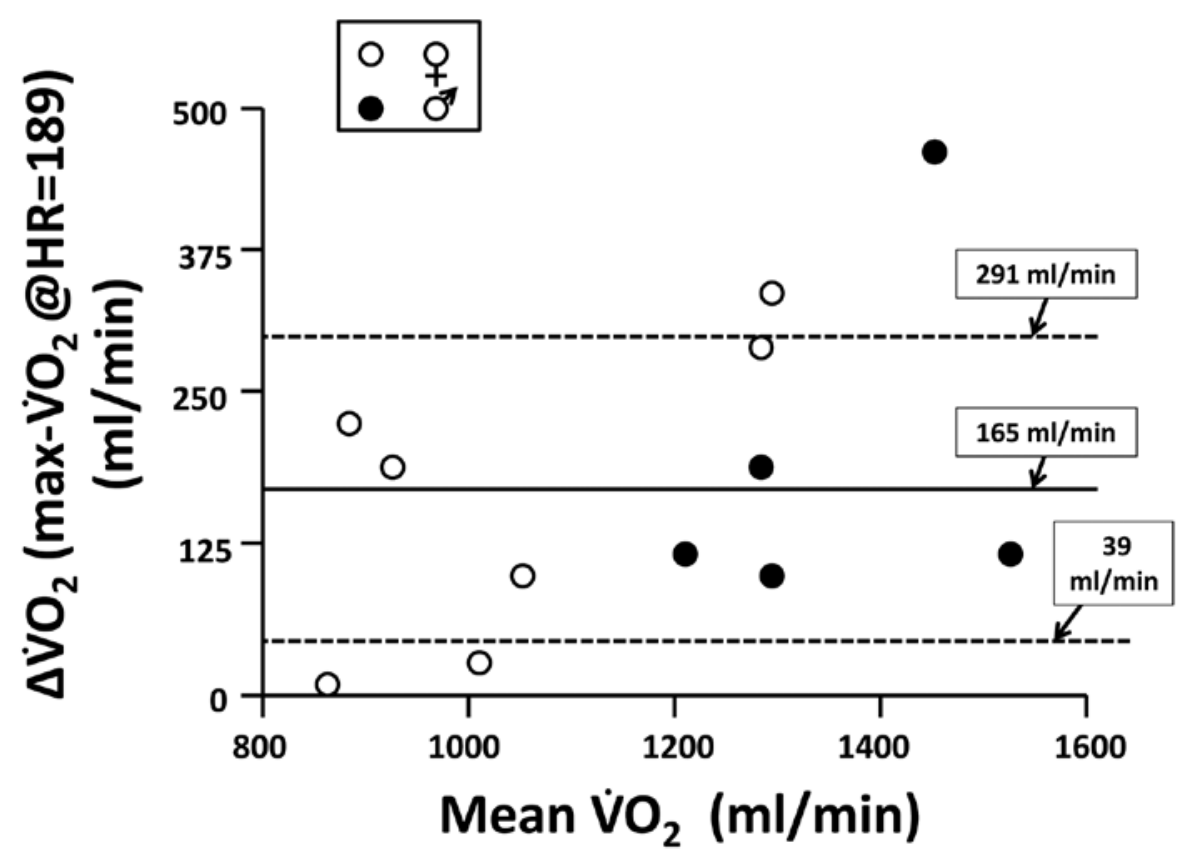

Figure 6 - Bland-Altman plot depicting oxygen uptake $\left(\mathrm{VO}_{2}\right)$ difference between $\mathrm{VO}_{2}$ max (validated for these subjects using the two-test protocol) and $\mathrm{VO}_{2}$ at heart rate $(\mathrm{HR})=189$ $\mathrm{b} / \mathrm{min}$. Mean bias is given by the solid line and $95 \%$ confidence intervals are dotted lines. Note subject numbers necessarily correspond to only those subjects in whom $\mathrm{VO}_{2}$ max was determined and HR reached at least $189 \mathrm{~b} / \mathrm{min}$.

herein is whether children who demonstrate EIAH (27) can perform the two-test protocol successfully. This was because all children maintained arterial oxygenation throughout the tests and thus, the possibility that EIAH might contribute to fatigue and preclude an individual from cycling for sufficient duration at $105 \%$ of the peak IWT power cannot be dismissed at this time.

\section{Determinants of $\mathrm{VO}_{2} \max$}

$\mathrm{VO}_{2}$ max reflects the capacity of all (pulmonary, cardiovascular, muscle) systems in the $\mathrm{O}_{2}$ transport pathway $(8,33,38,42,43)$. Given the extraordinary growth and muscle metabolic changes that occur through puberty it may well be that the determinants of $\mathrm{VO}_{2} \mathrm{max}$ in prepubertal children differ from those in adults. However, until rigorous protocols are developed to determine $\mathrm{VO}_{2} \max$ unambiguously in prepubertal children this issue remains undetermined. This situation give rise to speculation, for example, that children are less able to demonstrate $\mathrm{a} \mathrm{VO}_{2}$ plateau at $\mathrm{VO}_{2}$ max because their inferior anaerobic capacity limits exercise tolerance (which is low compared with adults; 18 ) or that the $\mathrm{VO}_{2}$ plateau may not indicate "the limits of cardiovascular function" in this population (36). In contrast, the present 
investigation demonstrates that, using a simple two-test protocol, a plateau of $\mathrm{VO}_{2}$ against work rate can be achieved in $75 \%$ of instances across a broad range of aerobic capacities. Additional tests may improve this success rate and help resolve whether fatigue or lack of motivation prevented defining $\mathrm{VO}_{2} \max$ in the remaining $25 \%$ of children herein. What is evident from the literature is that supra-critical power exercise (but below peak power achieved on the IWT) in children may not always achieve $\mathrm{VO}_{2} \max (5,6,48)$ as it almost invariably does in adults $(19,21,30-32)$. This being the case, and, consistent with the 'gold standard' definition of $\mathrm{VO}_{2} \mathrm{max}$, to validate $\mathrm{VO}_{2}$ max, investigators may be forced to resort to supra-IWT peak work rates which are sustainable for only a short period of time ( $66 \pm 18 \mathrm{~s}$ herein). Fortunately, children evince fast kinetics that drive $\mathrm{VO}_{2}$ rapidly to its maximum (within $50 \mathrm{~s}$ for the subject in Figure 1 (upper right panel)). It is not surprising therefore that the 90 s mean duration of the supramaximal CWR test employed by Barker et al. (6) was effective in substantiating attainment of $\mathrm{VO}_{2}$ max. In contrast, adult populations, particularly the aged and less aerobically fit, may require approximately twice the exercise duration necessary in children (i.e., at least $120 \mathrm{~s}$ or longer) to achieve $\mathrm{VO}_{2}$ max at supramaximal work rates (16).

Resolution of an unambiguous $\mathrm{VO}_{2}$ max in this prepubertal population is important in-and-of itself given the long-term cardiovascular health benefits conferred by, or associated with, exercise capacity and a high $\mathrm{VO}_{2} \max (15,22)$. Moreover it offers the opportunity to address questions of significant physiological and pathophysiological interest regarding $\mathrm{VO}_{2}$ max determinants in these populations.

\section{EFL in Children}

Anatomically children have smaller airways in comparison with lung size than adults (24) which, combined with greater ventilations at any given metabolic rate, leads to a high prevalence of EFL irrespective of $\mathrm{VO}_{2} \max$ per se $(28,29,40)$. EFL leads to dynamic hyperinflation (40) thereby mechanically disadvantaging the inspiratory muscles and increasing the likelihood of respiratory muscle fatigue which has been documented in adults during high intensity exercise (20). However, as demonstrated in a more highly fit population of children (6) and across a broad range of lower metabolic capacities herein, any such effect did not preclude either girls or boys from validating $\mathrm{VO}_{2}$ max using the two-test protocol. This issue was of particular concern in girls who, even at low fitness levels, may exhibit increased susceptibility to the mechanical constraints of ventilation (40).

\section{Indirect Criteria for Validating $\mathrm{VO}_{2} \max$}

1. RER. In the healthy adult population RER during maximal exercise may range from 1.0 to 1.44 being higher in the more rapidly incremented testing protocols $(9,32,39,45,46)$. Cut-offs of $1.0,1.1$ and 1.15 have been selected to demarcate subjects who have achieved a valid $\mathrm{VO}_{2} \max$ from those who have not (rev. 32). The maximal RER for a given individual is a complex entity that will depend: A. On total $\mathrm{CO}_{2}$ evolution (i.e., $\mathrm{VCO}_{2}$, numerator) which in itself is dependent upon pulmonary function (as it determines the maximal voluntary ventilation, MVV), the peripheral and (to a lesser degree) the net central chemoreceptor drive to breathe, the breathing pattern (as it determines dead space ventilation), multiple sources of $\mathrm{CO}_{2}$ 
(i.e., metabolic, $\mathrm{H}^{+}$buffering (amount and rate which itself is dependent upon rate of work rate progression, 46), unloading of $\mathrm{CO}_{2}$ stores). B. On the denominator $\mathrm{VO}_{2}$.

As prepubertal children have a lower capacity to generate lactic acid (e.g., 18), the rate of $\mathrm{H}^{+}$appearance in the blood and consequent buffering by $\mathrm{HCO}_{3}^{-}$will be lower than in adults. This consideration provides a mechanistic basis for the lower RERs typically observed during maximal exercise in children and therefore the RER criterion of 1.0 (37) versus the more common 1.1 or 1.15 in adults (32). However, the data presented herein extend those of Barker et al. (6) providing the first objective demonstration, over a broad range of aerobic fitness and in the presence of documented EFL, that a plateau of $\mathrm{VO}_{2}$ versus work rate can be achieved over a range of RERs from 0.97 to 1.10 for girls (though one subject at RER $=1.14$ was clearly at a submaximal $\mathrm{VO}_{2}$ ) and 0.99-1.07 for boys (and, again, there was one subject at a higher RER of 1.09 at a submaximal $\mathrm{VO}_{2}$ ). Hence most of the children in the present investigation would either have been rejected for $\mathrm{RER}<1.0$ ( 3 girls, 3 boys) or, because their RER rose above 1.0, could have stopped exercising at a submaximal $\mathrm{VO}_{2}$ which could not have been discriminated (and thus rejected) based upon the presumption that RER $=1.0$ denotes $\mathrm{VO}_{2} \mathrm{max}$ in children. The data presented herein thus present irrefutable evidence that the RER criterion of 1.0 (or, indeed, any unitary value for such) is erroneous as a criterion measurement for $\mathrm{VO}_{2} \max$ (see also ref. 6).

2. HR. The problems with presuming a one-size-fits all (i.e., $\geq 90 \%$ age predicted HRmax) are at least as great as those for RER when considering either adults or especially children. The standard deviation for the estimate of maximal HR (HRmax) in adults is $\pm 11 \mathrm{~b} / \mathrm{min}$ (23) and this may explain, in part, why eight girls and seven boys did not satisfy the criterion $\mathrm{HR}$ for $\mathrm{VO}_{2}$ max herein: this despite the fact that seven of these girls and two of these boys demonstrated an unambiguous $\mathrm{VO}_{2}$ plateau using the two-test procedure. As with RER, there was a substantial range of $\mathrm{HRs}$ at $\mathrm{VO}_{2}$ max for girls (i.e., 177-203 b/min) and one girl reached a HR of $205 \mathrm{~b} / \mathrm{min}$ at a submaximal $\mathrm{VO}_{2}$. For boys the $\mathrm{HR}$ range at $\mathrm{VO}_{2}$ max was 176-204 b/min with two boys at 204 and 206 b/min at submaximal $\mathrm{VO}_{2}$ s. Figures 5 and 6 demonstrate the inability of the prescribed HR criterion to validate achievement of $\mathrm{VO}_{2} \max$ and the potential for error this procedure allows.

For children this problem is emphasized by contrasting the HRmax data for two geographically distinct populations of children. Specifically, Cooper et al. (12) reported that, in N. American children aged 8-18 years, HRmax averaged $187 \mathrm{~b} / \mathrm{min}$ with a lower $95 \%$ confidence interval of $160 \mathrm{~b} / \mathrm{min}$. This data were markedly different from the $205 \mathrm{~b} / \mathrm{min}$ HRmax reported for Scandinavian children by Astrand and Rodahl (3). These and other considerations in combination with the data of Barker et al. (6) underline the American College of Sports Medicine (1991) mandate that specific HRs not be employed as definitive end-point criteria for exercise test termination.

\section{Experimental Considerations}

The two test protocol used herein validated $\mathrm{VO}_{2} \max$ in $75 \%$ of this female and male cohort of children of which less than $1 / 3$ of these demonstrated an unambiguous leveling off of the $\mathrm{VO}_{2}$-WR relationship during the IWT. However, what remains a concern is the $25 \%$ in which $\mathrm{VO}_{2}$ max could not be validated among whom several 
demonstrated a considerable (280 to $\sim 400 \mathrm{ml} / \mathrm{min}$ ) $\mathrm{VO}_{2}$ difference between peak values achieved on the IWT versus the CWR test. An a priori approach in future investigations would incorporate specific focus on the testing paradigm that yielded the lower $\mathrm{VO}_{2}$ value (i.e., IWT, CWR) and assess the reproducibility of the value obtained. Possibly IWTs with different rates of WR increase or CWR tests at a range of supramaximal work rates (e.g., 105, 110, 115\%) could be performed to increase the opportunity to achieve a $\mathrm{VO}_{2}-\mathrm{WR}$ leveling off. What remains especially challenging in some subjects in this population is motivation combined potentially with a lower capacity to generate energy from nonoxidative sources (18). This situation may create a very small window of opportunity to achieve $\mathrm{VO}_{2}$ max before fatigue particularly in those subjects with slower $\mathrm{VO}_{2}$ kinetics.

\section{Conclusions}

The straightforward two-test protocol described herein is feasible for prepubertal children across a broad range of aerobic capacity $\left(\mathrm{VO}_{2} \mathrm{max}\right)$ and irrespective of the presence of EFL and produces a discernible $\mathrm{VO}_{2}$-WR plateau or leveling-off thereby discriminating achievement of $\mathrm{VO}_{2} \max$ in $75 \%$ of the 27 children tested. This success rate is over twice that reported commonly in the pediatric literature (36) and likely results, in part, from the very rapid $\mathrm{VO}_{2}$ kinetics in this population that enables $\mathrm{VO}_{2}$ max to be achieved within one min during "supramaximal" exercise (Figure 1, upper right panel). With sufficiently motivated children, a second square-wave test performed in the residual $25 \%$ may increase this success rate further. As with adults and demonstrated recently for children (6), use of secondary criteria based upon RER or HR is problematic and lacks any ability to discriminate submaximal from maximal $\mathrm{VO}_{2} \mathrm{~s}$. In addition, such arbitrary cut-offs may justify accepting invalid (i.e., submaximal) $\mathrm{VO}_{2} \mathrm{~s}$ or, alternatively, force rejection of children who elicited $\mathrm{VO}_{2}$ max.

\section{References}

1. Andreacci J.L., R.J. Robertson, J.J. Dubé, D.J. Aaron, C.B. Dixon, and S.A. Arslanian. Comparison of maximal oxygen consumption between obese black and white adolescents. Pediatr. Res. 58:478-482, 2005. PubMed doi:10.1203/01.pdr.0000176909.66057.a3

2. Armstrong, N., J. Welsman, and R. Winsley. Is peak $\mathrm{VO}_{2}$ a maximal index of children's aerobic fitness? Int. J. Sports Med. 17:356-359, 1996. PubMed doi:10.1055/s-2007-972860

3. Astrand, P-O., and K. Rodahl. Textbook of Work Physiology: Physiological Bases of Exercise, 3rd ed. London: McGraw-Hill, 1986.

4. Astrand, I. Aerobic work capacity in men and women with special reference to age. Acta Physiol. Scand. Suppl. 49:1-92, 1960. PubMed

5. Barker, A.R., B. Bond, C. Toman, C.A. Williams, and N. Armstrong. Critical power in adolescents: physiological bases and assessment using all out exercise. Eur. J. Appl. Physiol. 112:1359-1370, 2011. PubMed doi:10.1007/s00421-011-2088-8

6. Barker, A.R., C.A. Williams, A.M. Jones, and N. Armstrong. Establishing maximal oxygen uptake in young people during a ramp cycle test to exhaustion. Br. J. Sports Med. 45:498-503, 2011. PubMed doi:10.1136/bjsm.2009.063180

7. Bar-Or, O., and T.W. Rowland. Pediatric Exercise Medicine. Human Kinetics, Champaign, Il, p. 362. 2004.

8. Bebout, D.E., D. Story, J. Roca, et al. Effects of altitude acclimatization on pulmonary gas exchange during exercise. J. Appl. Physiol. 67:2286-2295, 1989. PubMed 
9. Buchfuhrer, M.J., J.E. Hansen, T.E. Robinson, D.Y. Sue, K. Wasserman, and B.J. Whipp. Optimizing the exercise protocol for cardiopulmonary assessment. J. Appl. Physiol. 55:1558-1564, 1983. PubMed

10. Chapman, R.F., M. Emery, and J.M. Stager. Extent of expiratory flow limitation influences the increase in maximal ventilation in hypoxia. Respir. Physiol. 113:65-74, 1998. PubMed doi:10.1016/S0034-5687(98)00043-7

11. Cooper, D.M., D. Weiler-Ravell, B.J. Whipp, and K. Wasserman. Aerobic parameters of exercise as a function of body size during growth in children. J. Appl. Physiol. 56:628-634, 1984. PubMed

12. Cooper, D.M., D. Weiler-Ravell, B.J. Whipp, and K. Wasserman. Growth-related changes in oxygen uptake and heart arte during progressive exercise in children. Pediatr. Res. 18:845-851, 1984. PubMed doi:10.1203/00006450-198409000-00008

13. Davis, J.A., B.J. Whipp, N. Lamarra, D.J. Huntsman, M.H. Frank, and K. Wasserman. Effect of ramp slope on determination of aerobic parameters from the ramp exercise test. Med. Sci. Sports Exerc. 14:339-343, 1982. PubMed

14. Day, J.R., H.B. Rossiter, E.M. Coats, A. Skasick, and B.J. Whipp. The maximally attainable $\mathrm{VO}_{2}$ during exercise in humans: the peak vs. maximum issue. J. Appl. Physiol. 95:1901-1907, 2003. PubMed

15. Gaesser, G.A. Exercise for prevention and treatment of cardiovascular disease, type 2 diabetes, and metabolic syndrome. Curr. Diab. Rep. 7:14-19, 2007. PubMed doi:10.1007/s11892-007-0004-8

16. Hill, D.W., D.C. Poole, and J.C. Smith. The relationship between power and the time to achieve $\mathrm{VO}_{2} \max$. Med. Sci. Sports Exerc. 34:709-714, 2001. PubMed

17. Howley, E.T., D.R. Bassett, and H.G. Welch. Criteria for maximal oxygen uptake: review and commentary. Med. Sci. Sports Exerc. 27:1292-1301, 1995. PubMed

18. Inbar, O., and O. Bar-Or. Anaerobic characteristics in male children and adolescents. Med. Sci. Sports Exerc. 18:264-269, 1983. PubMed

19. Jones, A.M., B. Grassi, P.M. Christensen, P. Krustrup, J. Bangsbo, and D.C. Poole. Slow component of $\mathrm{VO}_{2}$ kinetics: mechanistic bases and practical applications. Med. Sci. Sports Exerc. 43:2046-2062, 2011. PubMed doi:10.1249/MSS.0b013e31821fcfc1

20. Johnson, B.D., M.A. Babcock, O.E. Suman, and J.A. Dempsey. Exercise-induced diaphragmatic fatigue in healthy humans. J. Physiol. 460:385-405, 1993. PubMed

21. Jones, A.M., A. Vanhatalo, M. Burnley, R.H. Morton, and D.C. Poole. Critical power: implications for determination of $\mathrm{VO}_{2}$ max and exercise tolerance. Med. Sci. Sports Exerc. 42:1876-1890, 2010. PubMed doi:10.1249/MSS.0b013e3181d9cf7f

22. Lee, D.C., X. Sui, E.G. Artero, et al. Long-term effects of changes in cardiorespiratory fitness and body mass index on all-cause and cardiovascular mortality in men: the aerobics center longitudinal study. Circulation. 124:2483-2490, 2011. PubMed doi:10.1161/CIRCULATIONAHA.111.038422

23. Londeree, B.R., and M.L. Moeschberger. Influence of age and other factors on maximal heart rate. J Cardiac Rehabil. 4:44-49, 1984.

24. Mead, J. Dysanapsis in normal lungs assessed by the relationship between maximal flow, static recoil, and vital capacity. Am. Rev. Respir. Dis. 121:339-342, 1980. PubMed

25. Midgley, A.W., and S. Carroll. Emergence of the verification phase procedure for confirming 'true' $\mathrm{VO}_{2}$ max. Scand J Med Sci Sports. 19:313-322, 2009. PubMed doi:10.1111/j.1600-0838.2009.00898.x

26. Midgley, A.W., S. Carroll, D. Marchant, L.R. McNaughton, and J. Siegler. Evaluation of true maximal oxygen uptake based on a novel set of standardized criteria. Appl. Physiol. Nutr. Metab. 34:115-123, 2009. PubMed doi:10.1139/H08-146

27. Nourry, C., C. Fabre, F. Bart, J.M. Grosbois, S. Berthoin, and P. Mucci. Evidence of exercise-induced arterial hypoxemia in prepubescent trained children. Pediatr. Res. 55:674-681, 2004. PubMed doi:10.1203/01.PDR.0000114481.58902.FB 
28. Nourry, C., F. Deruelle, C. Fabre, G. Baquet, F. Bart, and J.M. Grosbois. Exercise flow-volume loops in prepubescent aerobically trained children. J. Appl. Physiol. 99:1912-1921, 2005. PubMed doi:10.1152/japplphysiol.00323.2005

29. Nourry, C., F. Deruelle, C. Fabre, et al. Evidence of ventilator constraints in healthy exercising prepubescent children. Pediatr. Pulmonol. 41:133-140, 2006. PubMed doi:10.1002/ppul.20332

30. Poole, D.C., T.J. Barstow, P. McDonough, and A.M. Jones. Control of oxygen uptake during exercise. Med. Sci. Sports Exerc. 40:462-474, 2008. PubMed doi:10.1249/ MSS.0b013e31815ef29b

31. Poole, D.C., S.A. Ward, G.W. Gardner, and B.J. Whipp. Metabolic and respiratory profile of the upper limit for prolonged exercise in man. Ergonomics. 31:1265-1279, 1988. PubMed doi:10.1080/00140138808966766

32. Poole, D.C., D.P. Wilkerson, and A.M. Jones. Validity of criteria for establishing maxi$\mathrm{mal}_{2}$ uptake during ramp exercise tests. Eur. J. Appl. Physiol. 102:403-410, 2008b. PubMed doi:10.1007/s00421-007-0596-3

33. Roca, J., A.G. Agusti, A. Alonso, et al. Effects of training on muscle $\mathrm{O}_{2}$ transport at $\mathrm{VO}_{2}$ max. J. Appl. Physiol. 73:1067-1076, 1992. PubMed

34. Rowland, T.W. Does peak $\mathrm{VO}_{2}$ reflect $\mathrm{VO}_{2}$ max in children?: evidence from supramaximal testing. Med. Sci. Sports Exerc. 25:689-693, 1993. PubMed

35. Rowland, T.W. Evolution of maximal oxygen uptake in children. Med. Sport Sci. 50:200-209, 2007. PubMed doi:10.1159/000101392

36. Rowland, T.W., and D.P.E. Cunningham. Oxygen uptake plateau during maximal treadmill exercise in children. Chest. 101:485-489, 1992. PubMed doi:10.1378/ chest.101.2.485

37. Rowland, T., S. Hagenbuch, D. Pober, and A. Garrison. Exercise tolerance and thermoregulatory responses during cycling in boys and men. Med. Sci. Sports Exerc. 40:282-287, 2008. PubMed doi:10.1249/mss.0b013e31815a95a7

38. Schaffartzik, W., E.D. Barton, D.C. Poole, et al. Effect of reduced hemoglobin concentration on leg oxygen uptake during maximnal exercise in humans. J. Appl. Physiol. 75:491-498, 1993. PubMed

39. Sidney, K.H., and R.J. Shephard. Maximum and submaximum exercise tests in men and women in the seventh, eighth, and ninth decades of life. J. Appl. Physiol. 43:280-287, 1977. PubMed

40. Swain, K.E., S.K. Rosencranz, B. Beckman, and C.A. Harms. Expiratory flow limitation during exercise in prepubescent boys and girls: prevalence and implications. J. Appl. Physiol. 108:1267-1274, 2010. PubMed doi:10.1152/japplphysiol.00123.2009

41. Tanner, J.M. Growth at Adolescence. Oxford, UK: Blackwell Scientific, 1962, pp. 325.

42. Wagner, P.D. Determinants of maximal oxygen transport and utilization. Annu. Rev. Physiol. 58:21-50, 1996. PubMed doi:10.1146/annurev.ph.58.030196.000321

43. Wagner, P.D. New ideas on limitations to $\mathrm{VO}_{2}$ max. Exerc. Sport Sci. Rev. 28:10-14, 2000. PubMed

44. Wasserman, K., W.L. Beaver, J.A. Davis, J.Z. Pu, D. Heber, and B.J. Whipp. Lactate, pyruvate, and lactate-to-pyruvate ratio during exercise and recovery. J. Appl. Physiol. 59:935-940, 1985. PubMed

45. Wasserman, K., J.E. Hansen, D.Y. Sue, B.J. Whipp, and R. Casaburi. Principles of Exercise Testing and Interpretation, 2nd ed. London: Lea and Febiger, 1994.

46. Whipp, B.J. Physiological mechanisms dissociating pulmonary $\mathrm{CO}_{2}$ and $\mathrm{O}_{2}$ exchange dynamics during exercise in humans. Exp. Physiol. 92:347-355, 2007. PubMed doi:10.1113/expphysiol.2006.034363

47. Whipp, B.J., J.A. Davis, F. Torres, and K. Wasserman. A test to determine parameters of aerobic function during exercise. J. Appl. Physiol. 50:217-221, 1981. PubMed

48. Williams, C.A., J. Dekerle, K. McGawley, S. Berthoin, and H. Carter. Critical power in adolescent boys and girls - an exploratory study. Appl. Physiol. Nutr. Metab. 33:1105-1111, 2008. PubMed doi:10.1139/H08-096 